Targeting the

\title{
Mitochondria-Proteostasis Axis to Delay Aging
}

\author{
Andreas Zimmermann ${ }^{1,2}$, Corina Madreiter-Sokolowski ${ }^{3}$, Sarah Stryeck ${ }^{4}$ and \\ Mahmoud Abdellatif5,6,7*
}

1 Institute of Molecular Biosciences, University of Graz, Graz, Austria, ${ }^{2}$ Field of Excellence BioHealth - University of Graz, Graz, Austria, ${ }^{3}$ Gottfried Schatz Research Center, Medical University of Graz, Graz, Austria, ${ }^{4}$ Institute of Interactive Systems and Data Science, Graz University of Technology, Graz, Austria, ${ }^{5}$ Department of Cardiology, Medical University of Graz, Graz, Austria, ${ }^{6}$ Metabolomics and Cell Biology Platforms, Institut Gustave Roussy, Villejuif, France, ${ }^{7}$ Centre de Recherche des Cordeliers, Equipe Labellisée Par la Ligue Contre le Cancer, Université de Paris, Sorbonne Université, INSERM U1138, Institut Universitaire de France, Paris, France

Human life expectancy continues to grow globally, and so does the prevalence of agerelated chronic diseases, causing a huge medical and economic burden on society. Effective therapeutic options for these disorders are scarce, and even if available, are typically limited to a single comorbidity in a multifaceted dysfunction that inevitably affects all organ systems. Thus, novel therapies that target fundamental processes of aging itself are desperately needed. In this article, we summarize current strategies that

OPEN ACCESS

Edited by:

Sveva Bollini,

University of Genoa, Italy

Reviewed by:

Lucio Barile,

University of Zurich, Switzerland Edoardo Bertero,

University Hospital Würzburg, Germany

*Correspondence: Mahmoud Abdellatif mahmoud.abdellatif@medunigraz.at

Specialty section:

This article was submitted to

Molecular Medicine,

a section of the journal

Frontiers in Cell and Developmental

Biology

Received: 20 January 2021

Accepted: 22 February 2021

Published: 11 March 2021

Citation:

Zimmermann A

Madreiter-Sokolowski C, Stryeck S and Abdellatif M (2021) Targeting the Mitochondria-Proteostasis Axis

to Delay Aging.

Front. Cell Dev. Biol. 9:656201. doi: 10.3389/fcell.2021.656201 successfully delay aging and related diseases by targeting mitochondria and protein homeostasis. In particular, we focus on autophagy, as a fundamental proteostatic process that is intimately linked to mitochondrial quality control. We present genetic and pharmacological interventions that effectively extend health- and life-span by acting on specific mitochondrial and pro-autophagic molecular targets. In the end, we delve into the crosstalk between autophagy and mitochondria, in what we refer to as the mitochondria-proteostasis axis, and explore the prospect of targeting this crosstalk to harness maximal therapeutic potential of anti-aging interventions.

Keywords: aging, proteostasis, mitochondria, autophagy, anti-aging targets

\section{INTRODUCTION}

Human lifespan is continuously rising, which not only reweaves the social fabric of our society but also entails huge economic and medical burden due to the unprecedented prevalence of chronic diseases. Therapeutic options to delay the onset of age-related maladies are scarce, which is often further complicated by associated comorbidities. For instance, in the US, $62 \%$ percent of those over 65 years suffer from more than one chronic condition (Jaul and Barron, 2017). Therefore,

\footnotetext{
Abbreviations: 4EBP, eukaryotic translation initiation factor 4E-binding protein; AMPK, AMP activated kinase; ATG, autophagy-related; $\mathrm{Bcl}-2$, apoptosis regulator $\mathrm{Bcl}-2$; $\mathrm{CoA}$, coenzyme $\mathrm{A}$; $\mathrm{CR}$, caloric restriction; $\mathrm{CRM}$, caloric restriction mimetic; DRP1, dynamin-related protein 1; eIF5A, eukaryotic translation initiation factor 5A; ETC, electron transport chain; IGF-1, insulin-like growth factor 1; LC3, microtubule-associated protein 1A/1B-light chain 3; MFN1, mitofusin 1; MFN2, mitofusin 2; mTOR, mechanistic target of rapamycin; OPA1, optic atrophy 1; OXPHOS, oxidative phosphorylation; PD, Parkinson's disease; PGC- $1 \alpha$, PPAR $\gamma$ coactivator $\alpha$; PI3K, phosphatidylinositol 3 kinase; PINK1, PTEN-induced putative kinase protein 1; PolyQ, polyglutamine tract protein; PPAR $\gamma$, peroxisome proliferator-activated receptor; ROS, reactive oxygen species; SIRT1, NAD ${ }^{+}$-dependent protein deacetylase sirtuin-1; TFEB, transcription factor EB; ULK1, UNC-51-like kinase 1; VPS34, phosphatidylinositol 3-kinase VPS34.
} 
therapies which target fundamental processes of aging itself rather than treating each comorbidity as a separate clinical entity are desperately needed.

Aging manifests in a continuous decline of organismal homeostasis. Accumulating defects on the cellular level can result in cellular dysfunction that impairs normal physiology. This damage can be of extrinsic origin e.g., mutagenic radiation and toxins, or intracellular origin, like harmful reactive oxygen species (ROS) generated by defective mitochondrial respiration (Bornstein et al., 2020), advanced glycation end products (Semba et al., 2010) or the accumulation of toxic protein aggregates (Hipp et al., 2019). The consequences of such harm are particularly devastating to post-mitotic, fully differentiated cells with low cellular turnover rates, such as neuronal cells and cardiomyocytes (Ernst et al., 2014; Eschenhagen et al., 2017). To mitigate the detrimental effects of extrinsic and intrinsic noxa, eukaryotic cells have developed various protective mechanisms. One such mechanism is proteostasis, a collective term for a network of protein quality control and degradation pathways that ensure the normal expression, folding and turnover of proteins. During aging, proteostasis, like other cellular functions, suffer from a progressive decline, which renders the body more vulnerable to damage and age-related diseases (David, 2012; Wiersma et al., 2016). In particular, neurodegenerative (Hipp et al., 2019) and cardiovascular diseases (Wiersma et al., 2016; Abdellatif et al., 2020) are increasingly attributed to such age-related decline in proteostasis.

In terms of anti-aging interventions, (macro)-autophagy, a major catabolic pathway for macromolecules and even whole organelles, has proven to be a pharmacologically pliable mechanism to improve cellular proteostasis. Accumulating evidence suggests that mitochondrial function and proteostasis, in particular autophagy, are highly intertwined (Andréasson et al., 2019). This imposes new constraints on anti-aging therapies because the positive outcome of selectively targeting one of these processes (e.g., autophagy activation) might be limited if the other process is negatively affected (e.g., excessive mitochondrial clearance). Even the most efficient anti-aging intervention known to date, which is caloric restriction without malnutrition (CR), fails when components of the mitochondria-proteostasis axis are defective (Zhou et al., 2019). At the same time, behavioral or pharmacological interventions, such as CR mimetics (CRMs) that replicate molecular signatures of $\mathrm{CR}$, are likely to have the best efficacy, when they are able to improve both proteostasis as well as mitochondrial function.

Here, we summarize current strategies that successfully delay aging and aging-associated diseases by targeting autophagy, and/or mitochondrial homeostasis. In addition, we explore options to specifically target the mitochondria-autophagy crosstalk to harness maximal anti-aging potential of this axis.

\section{TARGETING AUTOPHAGY TO DELAY AGING}

The autophagic machinery consists of core autophagy-related (ATG) proteins, which mediate the recognition of cargo structures and the recruitment of membranes for the engulfment of cellular material into double-membraned vesicles, called autophagosomes. Autophagy initiation can be triggered by upstream signaling pathways such as starvation or stresssignaling, which relay environmental changes to the UNC-51like kinase 1 (ULK1) complex through a network of kinases and phosphatases. Upon ULK1 activation, double membrane isolation membranes, called phagophores, form under the participation of class III phosphatidylinositol 3 kinase (PI3K) complex, the membrane recruitment factor ATG9 and the tripartite ATG12-ATG5-ATG16 protein complex. The expanding phagophore is stabilized by the small, membrane-anchored protein microtubule-associated protein light chain 3 (LC3), which also mediates the interaction with cargo receptors that decorate cellular material designated for degradation (Figure 1). After the growing phagophore closes around cellular cargo, the resulting autophagosomes fuse with lysosomes and form autolysosomes, where the autophagic cargo is degraded and recycled (Yin et al., 2016). Proteostasis through this general autophagic degradation pathway (also termed "macro"autophagy) is complemented by several specialized subroutines, e.g., chaperone-mediated autophagy or autophagic degradation of mitochondria, called mitophagy.

Basal autophagy is essential for the maintenance of normal body function. Mice with whole-body knockout of the autophagy core machinery proteins, like ATG5 and ATG7, die perinatally (Kuma et al., 2017), while conditional tissue-specific disruption, for instance in neurons or cardiomyocytes, leads to premature organ damage in the form of neurodegeneration or dilated cardiomyopathy, respectively (Hara et al., 2006; Taneike et al., 2010). In humans, brain biopsies indicate that core ATG genes such as ATG5, ATG7 (Lipinski et al., 2010), and BECLIN 1 (Shibata et al., 2006) are downregulated during physiological aging, except in healthy centenarians, who reportedly show elevated serum levels of the PI3K complex subunit Beclin 1 compared to younger individuals (Emanuele et al., 2014). Consistently, patients with Alzheimer's disease or mild cognitive impairment show reduced serum levels of ATG5 (Castellazzi et al., 2019). While these human observations should be interpreted with caution, because ATG expression levels per se do not necessary correlate with autophagic activity (Klionsky et al., 2021), it is generally accepted that autophagy levels decrease with age and under many pathological conditions (Levine and Kroemer, 2008). In support of this notion, artificial activation of autophagy by ubiquitously overexpressing ATG5 extends health and lifespan in mice (Pyo et al., 2013). Prolonged lifespan was also observed upon neuronal overexpression of ATG8a in Drosophila (Simonsen et al., 2008). Hence, activating autophagy may not only counteract aging-associated pathologies but also slow down the aging process in general and therefore constitutes an attractive target for pharmacological interventions.

Autophagy can be modulated either by (i) targeting upstream signaling pathways, in particular insulin/IGF-1 receptor activity and AMP/ATP ratio, (ii) directly targeting proteins of the autophagic machinery, or (iii) improving the clearance of autophagosomes and their cargo by enhancing lysosomal function (Table 1). In general, a distinction 


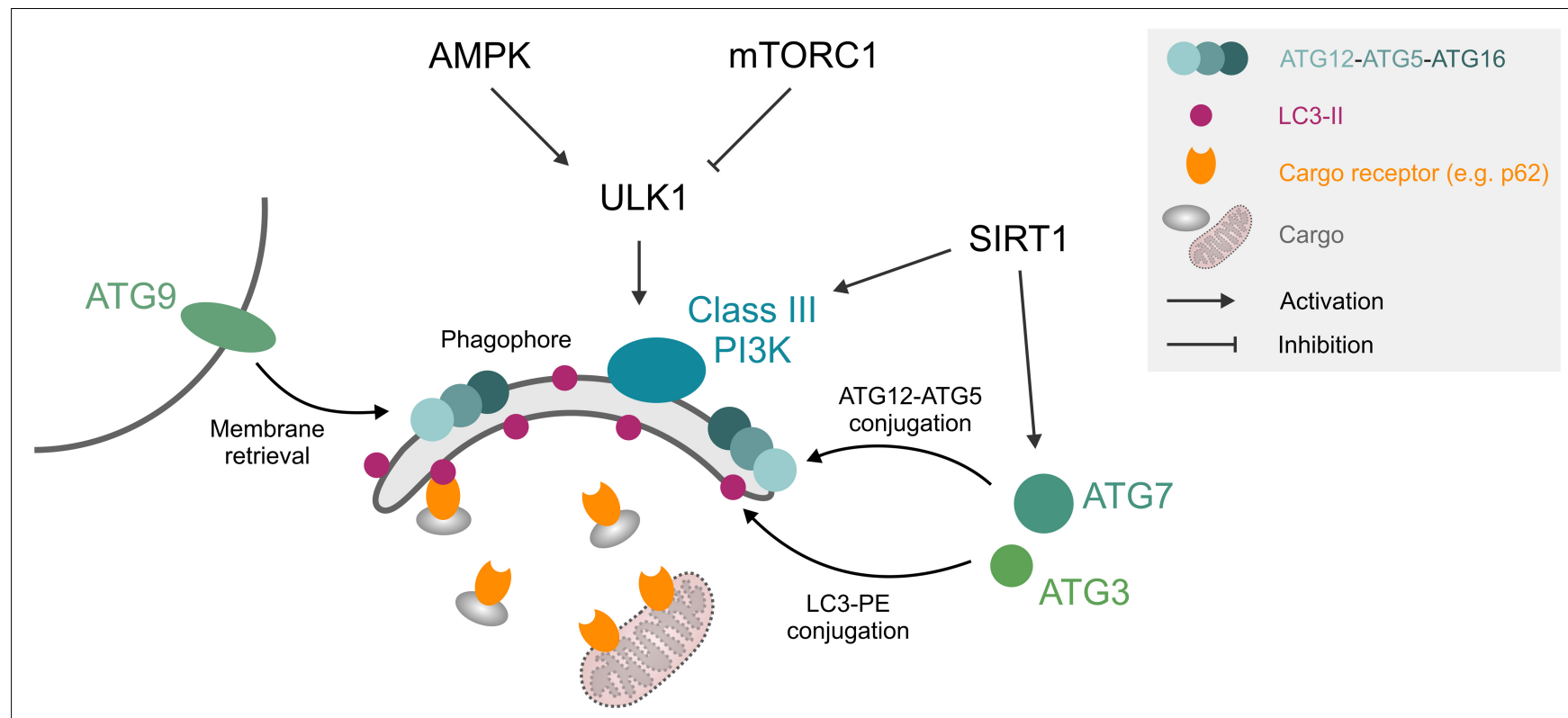

FIGURE 1 | Autophagy core machinery. Upstream nutrient/growth factor signaling and cellular energy status regulate mTORC1 and AMPK kinases, respectively, which in turn inhibit or activate ULK1 through different phosphorylation sites. ULK1 phosphorylates components of the phagophore formation machinery, consisting of a class III PI3K complex, ATG12-ATG5-ATG16 complex, ATG9, and LC3-II. LC3-II can interact with cargo (e.g., protein aggregates) through cargo receptors such as SQSTM1/p62 or organelles like mitochondria through mitochondrial surface markers. ATG3 and ATG7 mediate ATG12-ATG5 and LC3-PE conjugation. SIRT1 deacetylates and activates several ATG proteins. See text for details. Abbreviations: LC3-II, microtubule-associated protein light chain 3 (lipidated form); PE, phosphatidylethanolamine; PI3K, phosphatidylinositol 3 kinase; ULK1, Unc-51-like kinase 1.

between interventions that delay aging through autophagy induction and interventions that do so in association with, i.e., epiphenomenal, autophagy induction should be made. This is particularly important when studying CR mimetics or other bioactive compounds that target processes upstream of autophagy. For instance, the mTOR inhibitor rapamycin induces autophagy and extends Drosophila lifespan but fails to do so when ATG5 is downregulated. At the same time, the lifespan extension is also lost when the other branch of mTOR downstream signaling, namely translation control via S6 kinase and 4EBP is shunted (Bjedov et al., 2010). Here, laboratory model organisms such as Caenorhabditis elegans and Drosophila melanogaster as well as an increasing number of conditional and tissue-specific knockout mouse models are indispensable tools for a relatively fast and easy assessment of the causal role of autophagy or alternative processes.

\section{Targeting Upstream Signaling Pathways Regulating Autophagy}

Under nutrient-rich conditions, autophagy is repressed, while nutrient depletion or a high AMP/ATP ratio increases autophagic activity. Interestingly, these molecular signatures coincide with those elicited by $\mathrm{CR}$ and other anti-aging fasting regimes (Madeo et al., 2019). In fact, autophagy activation is a common hallmark among nutritional anti-aging interventions (Madeo et al., 2015), although the causal involvement of this activation in the context of CR and fasting remains surprisingly poorly investigated and has mainly been investigated in $C$. elegans mutants that only exhibit CR-like responses (Hansen et al., 2008). Nevertheless, autophagy is essential for the lifespan extending effects of AMP-activated kinase (AMPK) stimulation by salicylic acid derivatives (Shamalnasab et al., 2018). Other AMPK agonists, like metformin have been shown to counteract aging-related inflammation ("inflammaging") processes through autophagy activation (Bharath et al., 2020). Similarly, lifespan extension due to reduced insulin/insulin-like growth factor (IGF-1) receptor signaling in C. elegans daf-2 mutants requires functional autophagy (Melendez, 2003; Tóth et al., 2008) and the downstream effector of repressed insulin/IGF-1 signaling, the FOXO transcription factor DAF-16, promotes the expression of autophagy genes (Murphy et al., 2003). Pharmacological modulation of insulin/IGF-1 signaling, in particular by diazoxide has been proposed as a therapeutic avenue against cancer (Klement and Fink, 2016). Indeed, diazoxide reportedly restores autophagy in an osteoarthritis rat model and the beneficial effects were blocked by co-administration of the autophagy inhibitor 3-methyladenine (Meng et al., 2018). Another branch of $\mathrm{CR}$ downstream effects is regulated by the nicotinamide adenine dinucleotide $\left(\mathrm{NAD}^{+}\right)$-dependent deacetylase SIRT1, which directly deacetylates and thereby activates ATG proteins like Beclin 1, LC3, ATG5, and ATG7 (Sacitharan et al., 2020). SIRT1-deficient mice show early perinatal mortality accompanied by elevated acetylation of autophagy factors in heart, brain and liver tissue (Lee et al., 2008). In contrast, SIRT1 activation through $\mathrm{CR}, \mathrm{NAD}^{+}$supplementation or the polyphenol resveratrol delays cardiac aging (Abdellatif et al., 2021) and extends lifespan in an autophagy-dependent manner (Morselli et al., 2010a,b). In sum, there is a case to be made 
TABLE 1 | Defined molecular targets that delay aging by acting on the mitochondria-proteostasis axis.

\begin{tabular}{|c|c|c|c|c|c|}
\hline Mechanism & Target & Intervention & Organism/system & Outcome & References \\
\hline \multirow[t]{4}{*}{$\begin{array}{l}\text { Upstream } \\
\text { activation of } \\
\text { autophagy }\end{array}$} & $\uparrow \mathrm{AMPK}$ & $\begin{array}{l}\text { - Salicylates } \\
\text { - Metformin }\end{array}$ & $\begin{array}{l}\text { - C. elegans } \\
\text { - Mice }\end{array}$ & $\begin{array}{l}\text { Lifespan and healthspan } \\
\text { extension }\end{array}$ & $\begin{array}{l}\text { Martin-Montalvo et al., } \\
\text { 2013; Shamalnasab et al., } \\
\text { 2018; Bharath et al., } 2020\end{array}$ \\
\hline & $\downarrow$ Insulin/IGF-1 & $\begin{array}{l}\text { - Genetic mutation } \\
\text { (daf-2) } \\
\text { - Diazoxide }\end{array}$ & $\begin{array}{l}\text { - C. elegans } \\
\text { - Rats }\end{array}$ & Lifespan extension & $\begin{array}{l}\text { Melendez, 2003; Tóth et al., } \\
\text { 2008; Meng et al., } 2018\end{array}$ \\
\hline & $\uparrow \mathrm{SIRT1}$ & $\begin{array}{l}\text { - Resveratrol } \\
\text { - NAD+ precursors }\end{array}$ & $\begin{array}{l}\text { - C. elegans } \\
\text { - Mice }\end{array}$ & $\begin{array}{l}\text { - Lifespan extension } \\
\text { - Delayed cardiac aging }\end{array}$ & $\begin{array}{l}\text { Barger et al., 2008; Morselli } \\
\text { et al., 2010a,b; Abdellatif } \\
\text { et al., } 2021\end{array}$ \\
\hline & $\downarrow$ mTORC1 & - Rapamycin & $\begin{array}{l}\text { - C. elegans } \\
\text { - Drosophila } \\
\text { - Mice }\end{array}$ & Lifespan extension & $\begin{array}{l}\text { Bjedov et al., 2010; } \\
\text { Robida-Stubbs et al., 2012; } \\
\text { Neff et al., } 2013\end{array}$ \\
\hline \multirow{2}{*}{$\begin{array}{l}\text { Direct activation } \\
\text { of autophagy } \\
\text { machinery } \\
\text { proteins }\end{array}$} & $\uparrow$ ULK1 & - BL-918 molecule & - Mice & Neuroprotection & Ouyang et al., 2018 \\
\hline & $\uparrow$ Beclin 1 & $\begin{array}{l}\text { - Genetic mutation } \\
\left(\text { Beclin } 1^{F 121 A}\right) \\
\text { - Tat-Beclin } 1 \\
\text { peptide }\end{array}$ & - Mice & $\begin{array}{l}\text { - Extension of lifespan and } \\
\text { healthspan ( } \downarrow \text { renal, cardiac } \\
\text { and oncological pathologies) } \\
\text { - Ameliorated cardiac and } \\
\text { memory performance }\end{array}$ & $\begin{array}{l}\text { Shirakabe et al., 2016; } \\
\text { Fernández et al., 2018; Sun } \\
\text { et al., 2018; Glatigny et al., } \\
2019\end{array}$ \\
\hline $\begin{array}{l}\text { Lysosomal } \\
\text { clearance of } \\
\text { autophagic } \\
\text { cargo }\end{array}$ & $\uparrow$ TFEB & $\begin{array}{l}\text { - Genetic } \\
\text { overexpression } \\
\text { (HLH-30) } \\
\text { - Small-molecule } \\
\text { TFEB activators } \\
\text { - Trehalose }\end{array}$ & $\begin{array}{l}\text { - C. elegans } \\
\text { - Mice }\end{array}$ & $\begin{array}{l}\text { - Lifespan extension } \\
\text { - Hepatoprotection } \\
\text { - Attenuated vascular aging }\end{array}$ & $\begin{array}{l}\text { LaRocca et al., 2012; } \\
\text { Lapierre et al., 2013; Wang } \\
\text { et al., } 2017\end{array}$ \\
\hline $\begin{array}{l}\text { Mitochondrial } \\
\text { biogenesis }\end{array}$ & $\uparrow \mathrm{PGC}-1 \alpha$ & $\begin{array}{l}\text { - PPAR } \gamma \text { agonists } \\
\text { (GW1929) } \\
\text { - Cell-specific } \\
\text { genetic } \\
\text { overexpression }\end{array}$ & $\begin{array}{l}\text { - Human dopaminergic } \\
\text { neurons } \\
\text { - Mice (skeletal } \\
\text { myocytes) } \\
\text { - Mice (cardiomyocytes) }\end{array}$ & $\begin{array}{l}\text { - Neuroprotection } \\
\text { - Extension of median lifespan } \\
\text { in females and maximal lifespan } \\
\text { in males and enhanced } \\
\text { endurance capacity and } \\
\text { protection from age-related } \\
\text { sarcopenia, but aggravated } \\
\text { age-related bone loss } \\
\text { - Accentuated cardiac aging } \\
\text { and shorter lifespan with higher } \\
\text { overexpression, but } \\
\text { cardioprotection with moderate } \\
\text { overexpression }\end{array}$ & $\begin{array}{l}\text { Mäkelä et al., 2016; Garcia } \\
\text { et al., 2018; Whitehead } \\
\text { et al., 2018; Zhu et al., } \\
\text { 2019; Yang S. et al., } 2020\end{array}$ \\
\hline $\begin{array}{l}\text { Mitochondrial } \\
\text { fission }\end{array}$ & $\uparrow \mathrm{DRP1}$ & $\begin{array}{l}\text { - Genetic } \\
\text { upregulation } \\
\text { - Mitochondrial } \\
\text { division inhibitor-1 }\end{array}$ & $\begin{array}{l}\text { - Drosophila (midlife) } \\
\text { - Mice (skeletal muscle) } \\
\text { - Mice (intravenous } \\
\text { injection) }\end{array}$ & $\begin{array}{l}\text { - Lifespan and healthspan } \\
\text { extension } \\
\text { - Insulin resistance and } \\
\text { impaired muscle development } \\
\text { - Protection against cardiac } \\
\text { ischemia-reperfusion injury }\end{array}$ & $\begin{array}{l}\text { Ong et al., 2010; Jheng } \\
\text { et al., 2012; Touvier et al., } \\
\text { 2015; Rana et al., } 2017\end{array}$ \\
\hline $\begin{array}{l}\text { Mitochondrial } \\
\text { respiration }\end{array}$ & $\downarrow$ ETC & $\begin{array}{l}\text { - Genetic disruption } \\
\text { (Mit mutants) } \\
\text { - Cytochrome c } \\
\text { oxidase moderate } \\
\text { inhibitor }\end{array}$ & $\begin{array}{l}\text { - C. elegans } \\
\text { - Mice }\end{array}$ & $\begin{array}{l}\text { - Lifespan extension } \\
\text { - Healthspan extension, } \\
\text { including reduced visceral fat } \\
\text { and enhanced glucose } \\
\text { homeostasis }\end{array}$ & $\begin{array}{l}\text { Rea et al., 2007; Tavallaie } \\
\text { et al., } 2020\end{array}$ \\
\hline
\end{tabular}

for autophagy as one of the main effectors of the modulation of nutrient/growth factor signaling.

\section{Targeting the Autophagy Machinery Proteins}

Autophagy initiation is controlled by ULK1, which is regulated by the upstream kinases AMPK and mTOR complex 1 and in turn, activates other autophagy initiation factors like Beclin 1. Pharmacological activation of ULK1 with the structure-based design molecule BL-918 induces autophagy and has protective effects in a Parkinson's disease mouse model. This protection is lost when the autophagy blocker 3-methyladenine is coadministered (Ouyang et al., 2018). The ULK1 downstream target Beclin 1 is a regulator of the Beclin 1/VPS34 lipid kinase and, under basal conditions, is kept in an inactive state by a physical interaction with $\mathrm{Bcl}-2$. Under nutrient depletion or stress conditions, this interaction is lost and Beclin 1 can engage with VPS34 to stimulate autophagy initiation. Disrupting this 
interaction through a Beclin $1^{F 121 A}$ point mutation increases autophagic activity and extends lifespan in mice (Fernández et al., 2018). Chemical probes that disrupt Beclin $1 / \mathrm{Bcl}-2$ interaction have been discovered but are yet to be tested for their ability to extend lifespan in vivo (Chiang et al., 2018). Beclin 1 is also inhibited by interaction with Rubicon (Matsunaga et al., 2009), a protein that accumulates during aging (Nakamura et al., 2019). Rubicon depletion leads to lifespan extension in Drosophila (Nakamura et al., 2019), but to date, no pharmacological inhibitors have been identified. That said, the autophagy-promoting function of Beclin 1 can be mimicked by administration of a modified peptide corresponding to amino acids 267-284 of the protein (termed "Tat-Beclin 1 peptide") in vivo (Shoji-Kawata et al., 2013). Importantly, autophagy activation by Tat-Beclin 1 improves memory performance in aged mice (Glatigny et al., 2019) and protects from heart failure in mice plagued with risk factors, albeit at a young age (Shirakabe et al., 2016; Abdellatif et al., 2018; Sun et al., 2018).

The small membrane-bound protein LC3 does not only provide a membrane anchor for other components of the autophagic machinery but can also directly interact with autophagic cargo or adapter proteins such as sequestosome 1 (SQSTM1/p62). Recently, small molecules have been developed that can promote the interaction of LC3 with specific target proteins, e.g., the Huntington's disease-associated PolyQ protein huntingtin to mediate their autophagic degradation (Li et al., 2019). This strategy also works in the other direction, as demonstrated for a recently discovered small molecule that can disrupt the interaction of the malaria parasite factor UIS3 with LC3 (Setua et al., 2020). This modulation of interaction of specific target proteins with the autophagic machinery is an exciting therapeutic avenue, and more so as an increasing number of proteins has been shown to form aggregates during aging, which in turn may drive other proteotoxic events such as amyloid beta aggregation (Groh et al., 2017).

\section{Targeting Lysosomal Function}

The degradation of autophagic cargo requires healthy lysosomes. Indeed, blocking lysosomal function by inhibiting lysosomal acidification by bafilomycin A1 or neutralizing lysosomal $\mathrm{pH}$ by chloroquine is routinely used to measure the accumulation of autophagosomes experimentally (Klionsky et al., 2021). Lysosomal biogenesis, which constitutes an important factor in the efficacy of autophagy-inducing interventions (Di Malta et al., 2019), is regulated by several transcription factors, most prominently transcription factor EB (TFEB). TFEB activators such as trehalose (Rusmini et al., 2019), 3,4-dimethoxychalcone (Chen et al., 2019) as well as cytosolic $\mathrm{Ca}^{2+}$ levels (Medina et al., 2015) stimulate autophagic activity. Overexpression of the TFEB homolog HLH-30 is sufficient to extend C. elegans lifespan with concomitant autophagy activation (Lapierre et al., 2013), and small-molecule TFEB activators act hepatoprotective in mice and lifespan-extending in nematodes (Wang et al., 2017). TFEB expression declines with age, at least in human and murine immune cells, due to reduced activity of the translation initiation factor eIF5A (Zhang et al., 2019). This factor is activated by a unique post-translational modification, called hypusination, which requires the polyamine spermidine as a substrate. Intriguingly, spermidine levels also decline during aging, suggesting that reduced TFEB translation through impaired eIF5A hypusination might underlie the aging-associated loss of autophagic activity (Madeo et al., 2018; Zhang et al., 2019). This hypothesis is further corroborated by the fact that spermidine supplementation extends lifespan in various model organisms and protects against age-related cardiac decline in mice in an autophagy-dependent fashion (Eisenberg et al., 2009, 2016).

\section{TARGETING MITOCHONDRIA TO DELAY AGING}

Mitochondrial dysfunction is a hallmark of the aging process (López-Otín et al., 2013; Bornstein et al., 2020). Consistently, genetic mutations that dysregulate mitochondrial function clearly associate with accelerated aging phenotypes and increased susceptibility to disease (Bornstein et al., 2020). However, mitochondrial function does not necessarily show a linear decline during the course of aging. In fact, some reports claim a compensatory increase in mitochondrial activity during middle age, and only later on with advanced age that mitochondrial dysfunction arises (Pugh et al., 2013; Baker and Peleg, 2017). Considering such biphasic alteration of mitochondrial activity with age, the timing of mitochondrial manipulation might be a crucial issue in applying mitochondria-directed interventions for the treatment of age-related disorders. This timing aspect is further complicated by the fact that mitochondrial function, especially the activity of the mitochondrial electron transport chain (ETC), is tightly linked to ROS generation, which if produced at high levels can lead to mitochondrial DNA and proteins damage, thereby exacerbating cellular aging and toxicity (Madreiter-Sokolowski et al., 2018).

Structurally, mitochondria rely on a highly dynamic and interconnected network stretching throughout the whole cell. As such, functional mitochondria are constantly regulated through an extensive bidirectional communication with other cellular components, including the endoplasmic reticulum (ER) (Simmen and Herrera-Cruz, 2018), the plasma membrane (Westermann, 2015), endosomes (Das et al., 2016) and lysosomes (Wong et al., 2018). This communication can be mediated by $\mathrm{Ca}^{2+}$ ions, which strongly affect mitochondrial function by boosting the activity of $\mathrm{Ca}^{2+}$-dependent dehydrogenases of the Krebs cycle and, thereby, the efficacy of the ETC (Denton et al., 1975). Again, this beneficial effect can transition into toxicity, as overwhelming levels of mitochondrial $\mathrm{Ca}^{2+}$ might also induce cell death (Celsi et al., 2009), a mechanism reported for several age-related diseases (Calvo-Rodriguez et al., 2020). Consequently, fine-tuning of mitochondrial activity to secure sufficient energy supply, while avoiding exaggerated $\mathrm{Ca}^{2+}$ or ROS accumulation, seems essential in order to exploit mitochondria as a target to counteract aging.

In sum, in contrast to autophagy induction, where multiple proteins within the same pathway represent pliable molecular targets, choosing specific targets within the vast mitochondrial network and accurately modulate them to counteract aging (e.g., 
timing, dosage, duration, etc.) is more challenging (Rea et al., 2007). That said, available evidence suggests that mitochondria can be targeted to successfully delay aging through manipulating either of the following mitochondrial aspects: (i) biogenesis, (ii) dynamics, or (iii) metabolism (Table 1).

\section{Targeting Mitochondrial Biogenesis}

The peroxisome proliferator-activated receptor $\gamma(\operatorname{PPAR} \gamma)$ coactivator $\alpha$ (PGC- $1 \alpha)$ is a master regulator of mitochondrial biogenesis, which has been poised as a potential target to antagonize age-related mitochondrial decline. In fact, several studies have demonstrated that health-promoting interventions, like exercise and CR, associate with PGC-1 $\alpha$ activation (Kupr and Handschin, 2015), suggesting that it might be genetically or pharmacologically targeted to counteract aging and related disease. Indeed, PPAR $\gamma$ agonists, which are used to treat type-2-diabetes, were shown to elicit neuroprotective effects by a PGC- $1 \alpha$-mediated increase of mitochondrial biogenesis (Mäkelä et al., 2016). Directly targeting PGC- $1 \alpha$ by adenovirusassisted co-expression also rescued loss of dopaminergic neurons upon expression of the PD-associated $\alpha$-synuclein A53T mutant protein (Zheng et al., 2010). Furthermore, PGC$1 \alpha$ overexpression in skeletal muscle improved mitochondrial content and rejuvenated the molecular signature of aged mice, which exhibited a significant, albeit modest, extension of median lifespan in females and maximal lifespan in males (Garcia et al., 2018). In another study, constitutive overexpression of PGC-1 $\alpha$ in skeletal muscle cells recapitulates some features of exercisemediated anti-aging effects, yet hippocampal neurogenesis which is typically improved by exercise remained unaffected (Karlsson et al., 2019). Besides, functional evaluation of skeletal muscles in aged mice with PGC-1 $\alpha$-overexpressing revealed enhanced endurance capacity and protection from age-related sarcopenia, at least in males. However, these benefits were associated with aggravated age-related trabecular bone loss (Yang S. et al., 2020). In the heart, PGC-1 $\alpha$ overexpression, specifically in cardiac myocytes, improved mitochondrial function and cardiac performance; however, these effects were inflected with age, leading to an accentuated cardiac aging phenotype and shorter lifespan (Zhu et al., 2019). In contrast, another report suggested that when moderately overexpressed PGC-1 $\alpha$ exerts cardioprotective effects also in aged mice (Whitehead et al., 2018), indicating that fine-tuning of PGC- $1 \alpha$ activity is a crucial aspect to consider if the anti-aging potential of PGC- $1 \alpha$ is to be harnessed for the development of novel therapeutics.

\section{Targeting Mitochondrial Dynamics}

Mitochondria undergo dynamic changes in their morphology through active fusion and fission to cope with different cellular cues. In this process, the cytosolic dynamin-related protein 1 (DRP1) is considered a key player orchestrating mitochondrial fission, which is required for mitochondrial division, multiplication as well as budding off damaged segments for targeted degradation. Since DRP1 expression is reduced in aged cells, it was proposed as a potential target to counteract age-induced alterations in the mitochondrial network architecture (Mai et al., 2010). In support of this notion, short-term promotion of mitochondrial fission in midlife through DRP1 upregulation prolongs lifespan and healthspan in Drosophila (Rana et al., 2017). Pharmacological approaches to target mitochondrial fission by selectively inhibiting DRP1 were also successfully employed against ischemia/reperfusion injury (Ong et al., 2010) and in cell models of PD (Qi et al., 2013). In stark contrast, embryonic overexpression of DRP1 in the skeletal muscle of mice causes increased mitochondrial fragmentation and dysfunction, and impaired muscle development (Jheng et al., 2012; Touvier et al., 2015), thus indicating that the outcomes of targeting DRP1 and mitochondrial fission depend on the timing, duration and organism involved.

With regard to mitochondrial fusion, it is primarily mediated by two sets of proteins; mitofusin 1 and 2 (MFN1 and MFN2, respectively), as well as optic atrophy 1 (OPA1), which are responsible for the fusion of outer and inner mitochondrial membranes, respectively (Dorn, 2019). Mitochondrial fusion allows for direct metabolite exchange, improved ATP production, and enhanced stress resistance as it dilutes the influence of damaged mitochondria when they join a larger healthy network. In fact, caloric restriction and a myriad of other pro-longevity pathways require mitochondrial fusion to extend lifespan, at least in C. elegans (Chaudhari and Kipreos, 2017). However, it is important to note that increasing mitochondrial fusion per se is not sufficient to promote longevity, which indicate that targeting mitochondrial fusion has to be done in the context of promoting the dynamic balance between fusion and fission. In line with this idea, mice with a triple cardiac knockout of MFN1, MFN2, and DRP1 live longer than fusion-defective (MFN1/MFN2 double knockout) or fission-defective (DRP1 knockout) mice. However, such complete ablation of mitochondrial dynamics in Mfn1/Mfn2/Drp1 triple knockouts leads later on to impaired mitochondrial quality control, accelerated senescence, and cardiac dysfunction (Song et al., 2017). Taken together, the salutary benefits of targeting mitochondrial fusion or fission seem to be restricted to late-in-life interventions aimed to restore mitochondrial dynamics, rather than tipping off the balance in favor of fusion or fission.

\section{Targeting Mitochondrial Metabolism}

Although the primary function of mitochondria is to generate energy equivalents, moderate reduction of mitochondrial ATP synthesis through reversible pharmacological inhibition of the mitochondrial cytochrome $\mathrm{c}$ oxidase $(\mathrm{CcO})$ extends healthspan in mice (Tavallaie et al., 2020). Along similar lines, mutant C. elegans with disrupted ETC genes (Mit mutants) exhibit extended lifespan (Rea et al., 2007). However, by titrating the degree of mitochondrial ETC inhibition, these perplexing observations were reconciled, as lifespan extension appeared to be biphasic; i.e., moderate ETC inhibition was associated with lifespan extension, yet as the level of inhibition increased lifespan became shorter. Interestingly, global levels of ROS did not show any correlation with lifespan, suggesting that this effect cannot be attributed to differences in oxidative stress (Rea et al., 2007). The principal concept of a potential positive effect of antioxidants has been also challenged by the finding that small levels of ROS boost the development of antioxidant defense mechanisms, thereby positively affecting health- and lifespan (Ristow, 2014). In support of this finding, the three well-known 
antioxidants $\mathrm{N}$-acetylcysteine, ascorbic acid (vitamin $\mathrm{C}$ ) and resveratrol extended lifespan of $C$. elegans at low concentrations, but caused a reduced lifespan at high concentrations (Desjardins et al., 2017). This dosage-dependent effect might also explain the controversial outcomes of clinical trials testing the impact of antioxidant supplementation on the prevention of agerelated diseases like cardiovascular and oncological disorders (Lee et al., 2005; Cook et al., 2007). Thus, the usage of antioxidant supplements is questionable and does not seem to positively affect the process of aging. Alternately, interventions targeted to moderate mitochondrial metabolism and energy production might be more promising.

\section{THE CROSSTALK BETWEEN MITOCHONDRIA AND AUTOPHAGY}

Although both mitochondria- and autophagy-targeted interventions effectively delay aging, it remains unclear to what extent these overlap, and whether their simultaneous administration would result in any additional therapeutic value. A growing body of evidence suggests that, at least downstream, a crosstalk between these two longevity-promoting strategies exists. On the one hand, multiple steps of autophagy require ATP supply and, thus, functional mitochondria (Plomp et al., 1989; Li et al., 2017). On the other hand, autophagy regulates mitochondrial quantity and quality control through the degradation of damaged and potentially harmful mitochondria in a highly specialized form of autophagy, known as mitophagy (Abdellatif, 2019). Damaged or dysfunctional mitochondria accumulate the sentinel protein PTEN-induced kinase 1 (PINK1) at the surface, which is usually rapidly imported and then degraded in healthy mitochondria. PINK1 dimers phosphorylate ubiquitin moieties at the mitochondrial surface, which recruits the E3 ligase Parkin, leading to increased protein ubiquitination and the tagging of the damaged mitochondria for mitophagic degradation (Sekine and Youle, 2018).

Although it is challenging to specifically target mitophagy pharmacologically, available evidence supports the notion that mitophagy per se is significantly involved in counteracting

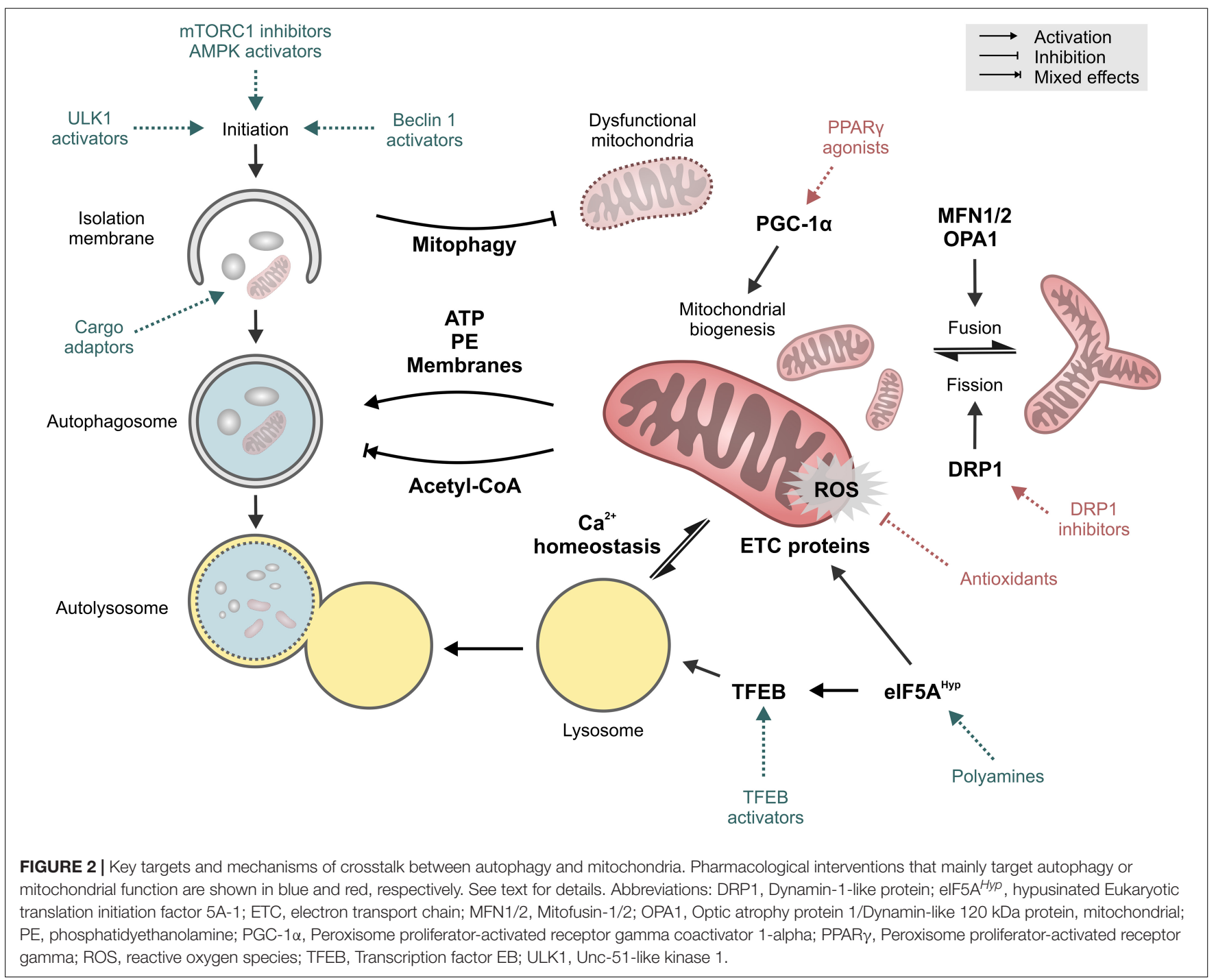


aging and related disease (Chen et al., 2020). For instance, mitophagy stimulation by the natural compound urolithin A improves mitochondrial respiratory capacity, thereby extending lifespan in $C$. elegans and attenuating age-related skeletal muscle dysfunction in rodents (Ryu et al., 2016). Similarly, induced mitophagy in spermidine-treated mice is associated with improved mitochondrial function, delayed aging, and protection against related cardiovascular diseases (Eisenberg et al., 2016; Tyrrell et al., 2020). A recent study in C. elegans suggested that mitophagy is a prerequisite for such protective effect of spermidine, at least against agerelated neurodegeneration (Yang X. et al., 2020). In line with this notion, neuron-specific overexpression of Parkin, known to promote mitophagy, is sufficient to attenuate agerelated proteotoxicity and extends lifespan in D. melanogaster (Rana et al., 2013). Meanwhile, global Parkin overexpression counteracts age-related sarcopenia and cardiac dysfunction in mice (Leduc-Gaudet et al., 2019; Gao et al., 2021). In support of a causal role for mitophagy in longevity promotion, impaired mitophagy due to PINK-1, DCT-1 and PDR-1 (the nematode homologs for NIX and Parkin, respectively) knock down in $C$. elegans significantly curtails lifespan extension induced by gold standard regimens for autophagy induction, including caloric restriction (in eat-2 mutants), and attenuated insulin/IGF-1 signaling (in long-lived daf-2 mutants) (Palikaras et al., 2015). Besides selective mitophagy, autophagy may regulate general mitochondrial network architecture, as it has been shown that lysosome-mitochondria membrane contact sites mark the location for subsequent mitochondrial fission (Wong et al., 2018).

As opposed to mitophagy, much less is known about the prospect of a reverse regulation of autophagic activity by mitochondria. Only a handful of studies examined the influence of mitochondria on autophagy, notwithstanding that mitochondria are expected to contribute to an energydependent process like autophagy (Plomp et al., 1989; $\mathrm{Li}$ et al., 2017). Thomas et al. (2018) demonstrated that mitochondrial complex I function does not only affect the cell ability to induce autophagy, but also determines the amplitude and duration of autophagy induction, at least upon mTOR inhibition. Accordingly, increasing mitochondrial energy production through a shift toward OXPHOS enhances autophagy activation by mTOR inhibitors (Thomas et al., 2018). Not only mitochondrial function, but also its morphology might have an impact on autophagic activity and might even go beyond that to determine the outcomes of autophagy activation in aging. In fact, stimulating mitochondrial dynamics have been shown to extend the lifespan of C. elegans and Drosophila in an autophagy-dependent manner (Rana et al., 2017; Liu et al., 2020). Meanwhile, increasing mitochondrial permeability renders autophagy activation non-beneficial or even harmful as demonstrated in C. elegans that mitochondrial leakage causes excessive mitochondrial clearance, thereby abolishing the lifespan-extending effect of autophagy induction by caloric restriction (Zhou et al., 2019).

Furthermore, mitochondrial metabolism might indirectly regulate autophagy levels through TCA intermediates, in particular citrate, which is the main substrate for cytosolic acetylCoA production. Acetyl-CoA is the sole donor for acetylation reactions, which have an important function in the posttranslational regulation of ATG protein activity. For instance, deacetylation of ATG5, ATG7, and LC3 by SIRT1 is considered an important step in starvation-induced autophagy (Lee et al., 2008). Other components like ULK1, ATG3, or tubulin have to get hyperacetylated to be active (Geeraert et al., 2010; Lin et al., 2012; Yi et al., 2012). Reducing cytosolic acetyl-CoA availability by inhibiting the mitochondrial citrate carrier activates autophagy in human cells (Mariño et al., 2014), while blocking mitochondrial acetate to acetyl-CoA conversion leads to elevated cytosolic acetyl-CoA production and blocked autophagic flux in yeast (Eisenberg et al., 2014). These results suggest that there is a constant crosstalk between mitochondrial metabolism and the activity of the autophagic machinery through an acetyl-CoAmediated surveillance system.

Another link through which mitochondria might regulate autophagy is lipid metabolism. First, mitochondria are a source for phagophore membranes during autophagosome biogenesis (Hailey et al., 2010). Second, mitochondria also provide phospholipids, like phosphatidylethanolamine (PE), which gets covalently linked to LC3 by ATG3 and ATG7 during autophagy initiation to form the active, lipidated LC3-II conjugate (Hsu and Shi, 2017; Martens and Fracchiolla, 2020). LC3 family proteins can also interact with the mitochondria-specific lipid cardiolipin, which can act as a biosensor for oxidative damage and an autophagic degradation signal when it translocates to the outer mitochondrial membrane (Antón et al., 2016). Interestingly, mitochondrial cardiolipin content seems to be linked to lysosomal function, at least in vitro (Chen et al., 2008; Bartel et al., 2019). However, it is not known if this indirect modulation of mitochondrial cardiolipin also induces mitophagy, as observed during oxidative damage-induced translocation of cardiolipin to the mitochondrial surface.

\section{CONCLUDING REMARKS}

Mitochondria and autophagy have long been implicated in the process of aging and age-related disorders. More recently though, emerging evidence of a crosstalk between these two longevity targets opens a new avenue for anti-aging interventions. In this perspective, we propose that future research should be aimed toward the identification of causal mechanistic nods linking these two longevity targets (Figure 2). Current observations from model organisms will also need to be verified in mammalian and human tissues. This will be particularly relevant for the organ systems that are mainly constituted of energy-demanding cells, like cardiomyocytes and neurons. Both are long-lived post-mitotic cells that are rich in mitochondria and largely depend on proteostatic mechanisms like autophagy for their quality control. Collectively, the gathered knowledge would guide future development of novel anti-aging therapeutics targeting the mitochondria-proteostasis axis, which might prove more effective against a wide-range of intractable cardiovascular and neurological diseases in the elderly. 


\section{DATA AVAILABILITY STATEMENT}

The original contributions presented in the study are included in the article/supplementary material, further inquiries can be directed to the corresponding author.

\section{AUTHOR CONTRIBUTIONS}

MA and AZ conceived and designed the manuscript. All authors contributed to collecting the literature and writing the first draft of the manuscript and approved the final version of the manuscript for publication.

\section{REFERENCES}

Abdellatif, M. (2019). Autophagy promotes longevity-except in the presence of "leaky" mitochondria. Cardiovasc. Res. 115, e118-e120. doi: 10.1093/cvr/ cvz224

Abdellatif, M., Ljubojevic-Holzer, S., Madeo, F., and Sedej, S. (2020). Autophagy in cardiovascular health and disease. Prog. Mol. Biol. Transl. Sci. 172, 87-106. doi: 10.1016/bs.pmbts.2020.04.022

Abdellatif, M., Sedej, S., Madeo, F., and Kroemer, G. (2018). Cardioprotective effects of autophagy induction in sepsis. Ann. Transl. Med. 6:S61. doi: 10.21037/ atm.2018.10.23

Abdellatif, M., Trummer-Herbst, V., Koser, F., Durand, S., Adão, R., VasquesNóvoa, F., et al. (2021). Nicotinamide for the treatment of heart failure with preserved ejection fraction. Sci. Transl. Med. 13:eabd7064. doi: 10.1126/ scitranslmed.abd7064

Andréasson, C., Ott, M., and Büttner, S. (2019). Mitochondria orchestrate proteostatic and metabolic stress responses. EMBO Rep. 20:e47865. doi: 10. 15252/embr.201947865

Antón, Z., Landajuela, A., Hervás, J. H., Montes, L. R., Hernández-Tiedra, S., Velasco, G., et al. (2016). Human Atg8-cardiolipin interactions in mitophagy: specific properties of LC3B, GABARAPL2 and GABARAP. Autophagy 12, 2386-2403. doi: 10.1080/15548627.2016.1240856

Baker, D. J., and Peleg, S. (2017). Biphasic modeling of mitochondrial metabolism dysregulation during aging. Trends Biochem. Sci. 42, 702-711. doi: 10.1016/j. tibs.2017.06.005

Barger, J. L., Kayo, T., Vann, J. M., Arias, E. B., Wang, J., Hacker, T. A., et al. (2008). A low dose of dietary resveratrol partially mimics caloric restriction and retards aging parameters in mice. PLoS One 3:e2264. doi: 10.1371/journal.pone. 0002264

Bartel, K., Pein, H., Popper, B., Schmitt, S., Janaki-Raman, S., Schulze, A., et al. (2019). Connecting lysosomes and mitochondria - a novel role for lipid metabolism in cancer cell death. Cell Commun. Signal. 17:87. doi: 10.1186/ s12964-019-0399-2

Bharath, L. P., Agrawal, M., McCambridge, G., Nicholas, D. A., Hasturk, H., Liu, J., et al. (2020). Metformin enhances autophagy and normalizes mitochondrial function to alleviate aging-associated inflammation. Cell Metab. 32, 44.e655.e6. doi: 10.1016/j.cmet.2020.04.015

Bjedov, I., Toivonen, J. M., Kerr, F., Slack, C., Jacobson, J., Foley, A., et al. (2010). Mechanisms of life span extension by rapamycin in the fruit fly Drosophila melanogaster. Cell Metab. 11, 35-46. doi: 10.1016/j.cmet.2009. 11.010

Bornstein, R., Gonzalez, B., and Johnson, S. C. (2020). Mitochondrial pathways in human health and aging. Mitochondrion 54, 72-84. doi: 10.1016/j.mito.2020. 07.007

Calvo-Rodriguez, M., Hou, S. S., Snyder, A. C., Kharitonova, E. K., Russ, A. N., Das, S., et al. (2020). Increased mitochondrial calcium levels associated with neuronal death in a mouse model of Alzheimer's disease. Nat. Commun. 11:2146. doi: 10.1038/s41467-020-16074-2

Castellazzi, M., Patergnani, S., Donadio, M., Giorgi, C., Bonora, M., Bosi, C., et al. (2019). Autophagy and mitophagy biomarkers are reduced in sera of patients

\section{FUNDING}

MA acknowledges funding received from the European Society of Cardiology in the form of an ESC Research Grant and from the Austrian Society of Cardiology (Präsidentenstipendium der ÖKG). AZ acknowledges support from BioTechMed Graz, NAWI Graz and the Field of Excellence BioHealth at the University of Graz. CM-S was currently funded by an Erwin Schroedinger Abroad Fellowship (J4205-B27). SS was supported by H2020-JTI-EuroHPC-2019-2 (951732), Digitale und soziale Transformation in der Hochschulbildung (BMBWF, "Austrian DataLab and Services"), and the Strategic Project Digitale TU Graz (Graz University of Technology).

with Alzheimer's disease and mild cognitive impairment. Sci. Rep. 9:20009. doi: 10.1038/s41598-019-56614-5

Celsi, F., Pizzo, P., Brini, M., Leo, S., Fotino, C., Pinton, P., et al. (2009). Mitochondria, calcium and cell death: a deadly triad in neurodegeneration. Biochim. Biophys. Acta 1787, 335-344. doi: 10.1016/j.bbabio.2009.02.021

Chaudhari, S. N., and Kipreos, E. T. (2017). Increased mitochondrial fusion allows the survival of older animals in diverse C. elegans longevity pathways. Nat. Commun. 8:182. doi: 10.1038/s41467-017-00274-4

Chen, G., Kroemer, G., and Kepp, O. (2020). Mitophagy: an emerging role in aging and age-associated diseases. Front. Cell Dev. Biol. 8:200. doi: 10.3389/fcell.2020. 00200

Chen, G., Xie, W., Nah, J., Sauvat, A., Liu, P., Pietrocola, F., et al. (2019). 3,4Dimethoxychalcone induces autophagy through activation of the transcription factors TFE3 and TFEB. EMBO Mol. Med. 11:e10469. doi: 10.15252/emmm. 201910469

Chen, S., Tarsio, M., Kane, P. M., and Greenberg, M. L. (2008). Cardiolipin mediates cross-talk between mitochondria and the vacuole. Mol. Biol. Cell 19, 5047-5058. doi: 10.1091/mbc.e08-05-0486

Chiang, W.-C., Wei, Y., Kuo, Y.-C., Wei, S., Zhou, A., Zou, Z., et al. (2018). High-throughput screens to identify autophagy inducers that function by disrupting beclin 1/Bcl-2 Binding. ACS Chem. Biol. 13, 2247-2260. doi: 10.1021/ acschembio.8b00421

Cook, N. R., Albert, C. M., Gaziano, J. M., Zaharris, E., MacFadyen, J., Danielson, E., et al. (2007). A randomized factorial trial of vitamins $\mathrm{C}$ and $\mathrm{E}$ and beta carotene in the secondary prevention of cardiovascular events in women: results from the Women's antioxidant cardiovascular study. Arch. Intern. Med. 167, 1610-1618. doi: 10.1001/archinte.167.15.1610

Das, A., Nag, S., Mason, A. B., and Barroso, M. M. (2016). Endosome-mitochondria interactions are modulated by iron release from transferrin. J. Cell Biol. 214, 831-845. doi: 10.1083/jcb.201602069

David, D. C. (2012). Aging and the aggregating proteome. Front. Genet. 3:247. doi: 10.3389/fgene.2012.00247

Denton, R. M., Randle, P. J., Bridges, B. J., Cooper, R. H., Kerbey, A. L., Pask, H. T., et al. (1975). Regulation of mammalian pyruvate dehydrogenase. Mol. Cell. Biochem. 9, 27-53. doi: 10.1007/BF01731731

Desjardins, D., Cacho-Valadez, B., Liu, J.-L., Wang, Y., Yee, C., Bernard, K., et al. (2017). Antioxidants reveal an inverted U-shaped dose-response relationship between reactive oxygen species levels and the rate of aging in Caenorhabditis elegans. Aging Cell 16, 104-112. doi: 10.1111/acel.12528

Di Malta, C., Cinque, L., and Settembre, C. (2019). Transcriptional regulation of autophagy: mechanisms and diseases. Front. Cell Dev. Biol. 7:114. doi: 10.3389/ fcell.2019.00114

Dorn, G. W. (2019). Evolving concepts of mitochondrial dynamics. Annu. Rev. Physiol. 81, 1-17. doi: 10.1146/annurev-physiol-020518-114358

Eisenberg, T., Abdellatif, M., Schroeder, S., Primessnig, U., Stekovic, S., Pendl, T., et al. (2016). Cardioprotection and lifespan extension by the natural polyamine spermidine. Nat. Med. 22, 1428-1438. doi: 10.1038/nm.4222

Eisenberg, T., Knauer, H., Schauer, A., Büttner, S., Ruckenstuhl, C., CarmonaGutierrez, D., et al. (2009). Induction of autophagy by spermidine promotes longevity. Nat. Cell Biol. 11, 1305-1314. doi: 10.1038/ncb1975 
Eisenberg, T., Schroeder, S., Andryushkova, A., Pendl, T., Küttner, V., Bhukel, A., et al. (2014). Nucleocytosolic depletion of the energy metabolite acetylcoenzyme a stimulates autophagy and prolongs lifespan. Cell Metab. 19, 431-444. doi: 10.1016/j.cmet.2014.02.010

Emanuele, E., Minoretti, P., Sanchis-Gomar, F., Pareja-Galeano, H., Yilmaz, Y., Garatachea, N., et al. (2014). Can enhanced autophagy be associated with human longevity? Serum levels of the autophagy biomarker beclin-1 are increased in healthy centenarians. Rejuvenation Res. 17, 518-524. doi: 10.1089/ rej.2014.1607

Ernst, A., Alkass, K., Bernard, S., Salehpour, M., Perl, S., Tisdale, J., et al. (2014). Neurogenesis in the striatum of the adult human brain. Cell 156, 1072-1083. doi: 10.1016/j.cell.2014.01.044

Eschenhagen, T., Bolli, R., Braun, T., Field, L. J., Fleischmann, B. K., Frisén, J., et al. (2017). Cardiomyocyte regeneration: a consensus statement. Circulation 136, 680-686. doi: 10.1161/CIRCULATIONAHA.117.029343

Fernández, ÁF., Sebti, S., Wei, Y., Zou, Z., Shi, M., McMillan, K. L., et al. (2018). Disruption of the beclin 1-BCL2 autophagy regulatory complex promotes longevity in mice. Nature 558, 136-140. doi: 10.1038/s41586-018-0162-7

Gao, B., Yu, W., Lv, P., Liang, X., Sun, S., and Zhang, Y. (2021). Parkin overexpression alleviates cardiac aging through facilitating K63polyubiquitination of TBK1 to facilitate mitophagy. Biochim. Biophys. Acta Mol. Basis Dis. 1867:165997. doi: 10.1016/j.bbadis.2020.165997

Garcia, S., Nissanka, N., Mareco, E. A., Rossi, S., Peralta, S., Diaz, F., et al. (2018). Overexpression of PGC- $1 \alpha$ in aging muscle enhances a subset of young-like molecular patterns. Aging Cell 17:e12707. doi: 10.1111/acel.12707

Geeraert, C., Ratier, A., Pfisterer, S. G., Perdiz, D., Cantaloube, I., Rouault, A., et al. (2010). Starvation-induced hyperacetylation of tubulin is required for the stimulation of autophagy by nutrient deprivation. J. Biol. Chem. 285, 24184-24194. doi: 10.1074/jbc.M109.091553

Glatigny, M., Moriceau, S., Rivagorda, M., Ramos-Brossier, M., Nascimbeni, A. C., Lante, F., et al. (2019). Autophagy is required for memory formation and reverses age-related memory decline. Curr. Biol. CB 29, 435.e8-448.e8. doi: 10.1016/j.cub.2018.12.021

Groh, N., Bühler, A., Huang, C., Li, K. W., van Nierop, P., Smit, A. B., et al. (2017). Age-dependent protein aggregation initiates Amyloid- $\beta$ aggregation. Front. Aging Neurosci. 9:138. doi: 10.3389/fnagi.2017.00138

Hailey, D. W., Rambold, A. S., Satpute-Krishnan, P., Mitra, K., Sougrat, R., Kim, P. K., et al. (2010). Mitochondria supply membranes for autophagosome biogenesis during starvation. Cell 141, 656-667. doi: 10.1016/j.cell.2010. 04.009

Hansen, M., Chandra, A., Mitic, L. L., Onken, B., Driscoll, M., and Kenyon, C. (2008). A role for autophagy in the extension of lifespan by dietary restriction in C. elegans. PLoS Genet. 4:e24. doi: 10.1371/journal.pgen.0040024

Hara, T., Nakamura, K., Matsui, M., Yamamoto, A., Nakahara, Y., SuzukiMigishima, R., et al. (2006). Suppression of basal autophagy in neural cells causes neurodegenerative disease in mice. Nature 441, 885-889. doi: 10.1038/ nature 04724

Hipp, M. S., Kasturi, P., and Hartl, F. U. (2019). The proteostasis network and its decline in ageing. Nat. Rev. Mol. Cell Biol. 20, 421-435. doi: 10.1038/s41580019-0101-y

Hsu, P., and Shi, Y. (2017). Regulation of autophagy by mitochondrial phospholipids in health and diseases. Biochim. Biophys. Acta Mol. Cell Biol. Lipids 1862, 114-129. doi: 10.1016/j.bbalip.2016.08.003

Jaul, E., and Barron, J. (2017). Age-related diseases and clinical and public health implications for the 85 years old and over population. Front. Public Health 5:335. doi: 10.3389/fpubh.2017.00335

Jheng, H.-F., Tsai, P.-J., Guo, S.-M., Kuo, L.-H., Chang, C.-S., Su, I.-J., et al. (2012). Mitochondrial fission contributes to mitochondrial dysfunction and insulin resistance in skeletal muscle. Mol. Cell. Biol. 32, 309-319. doi: 10.1128/MCB. 05603-11

Karlsson, L., González-Alvarado, M. N., Motalleb, R., Blomgren, K., Börjesson, M., and Kuhn, H. G. (2019). Constitutive PGC-1 $\alpha$ overexpression in skeletal muscle does not protect from age-dependent decline in neurogenesis. Sci. Rep. 9:12320. doi: 10.1038/s41598-019-48795-w

Klement, R. J., and Fink, M. K. (2016). Dietary and pharmacological modification of the insulin/IGF-1 system: exploiting the full repertoire against cancer. Oncogenesis 5:e193. doi: 10.1038/oncsis.2016.2
Klionsky, D. J., Abdel-Aziz, A. K., Abdelfatah, S., Abdellatif, M., Abdoli, A., Abel, S., et al. (2021). Guidelines for the use and interpretation of assays for monitoring autophagy (4th edition). Autophagy. 1-382. doi: 10.1080/15548627. 2020.1797280 [Epub ahead of print].

Kuma, A., Komatsu, M., and Mizushima, N. (2017). Autophagy-monitoring and autophagy-deficient mice. Autophagy 13, 1619-1628. doi: 10.1080/15548627. 2017.1343770

Kupr, B., and Handschin, C. (2015). Complex coordination of cell plasticity by a PGC-1 $\alpha$-controlled transcriptional network in skeletal muscle. Front. Physiol. 6:325. doi: $10.3389 /$ fphys.2015.00325

Lapierre, L. R., De Magalhaes Filho, C. D., McQuary, P. R., Chu, C.-C., Visvikis, O., Chang, J. T., et al. (2013). The TFEB orthologue HLH-30 regulates autophagy and modulates longevity in Caenorhabditis elegans. Nat. Commun. 4:2267. doi: $10.1038 /$ ncomms 3267

LaRocca, T. J., Henson, G. D., Thorburn, A., Sindler, A. L., Pierce, G. L., and Seals, D. R. (2012). Translational evidence that impaired autophagy contributes to arterial ageing. J. Physiol. 590, 3305-3316. doi: 10.1113/jphysiol.2012.229690

Leduc-Gaudet, J.-P., Reynaud, O., Hussain, S. N., and Gouspillou, G. (2019). Parkin overexpression protects from ageing-related loss of muscle mass and strength. J. Physiol. 597, 1975-1991. doi: 10.1113/JP277157

Lee, I. H., Cao, L., Mostoslavsky, R., Lombard, D. B., Liu, J., Bruns, N. E., et al. (2008). A role for the NAD-dependent deacetylase Sirt1 in the regulation of autophagy. Proc. Natl. Acad. Sci. U.S.A. 105, 3374-3379. doi: 10.1073/pnas. 0712145105

Lee, I.-M., Cook, N. R., Gaziano, J. M., Gordon, D., Ridker, P. M., Manson, J. E., et al. (2005). Vitamin $\mathrm{E}$ in the primary prevention of cardiovascular disease and cancer: the Women's Health Study: a randomized controlled trial. JAMA 294, 56-65. doi: 10.1001/jama.294.1.56

Levine, B., and Kroemer, G. (2008). Autophagy in the pathogenesis of disease. Cell 132, 27-42. doi: 10.1016/j.cell.2007.12.018

Li, F.-J., Xu, Z.-S., Soo, A. D. S., Lun, Z.-R., and He, C. Y. (2017). ATP-driven and AMPK-independent autophagy in an early branching eukaryotic parasite. Autophagy 13, 715-729. doi: 10.1080/15548627.2017.1280218

Li, Z., Wang, C., Wang, Z., Zhu, C., Li, J., Sha, T., et al. (2019). Allele-selective lowering of mutant HTT protein by HTT-LC3 linker compounds. Nature 575, 203-209. doi: 10.1038/s41586-019-1722-1

Lin, S.-Y., Li, T. Y., Liu, Q., Zhang, C., Li, X., Chen, Y., et al. (2012). GSK3-TIP60ULK1 signaling pathway links growth factor deprivation to autophagy. Science 336, 477-481. doi: 10.1126/science. 1217032

Lipinski, M. M., Zheng, B., Lu, T., Yan, Z., Py, B. F., Ng, A., et al. (2010). Genomewide analysis reveals mechanisms modulating autophagy in normal brain aging and in Alzheimer's disease. Proc. Natl. Acad. Sci. U.S.A. 107, 14164-14169. doi: 10.1073/pnas.1009485107

Liu, Y. J., McIntyre, R. L., Janssens, G. E., Williams, E. G., Lan, J., van Weeghel, M., et al. (2020). Mitochondrial translation and dynamics synergistically extend lifespan in C. elegans through HLH-30. J. Cell Biol. 219:e201907067. doi: 10. 1083/jcb.201907067

López-Otín, C., Blasco, M. A., Partridge, L., Serrano, M., and Kroemer, G. (2013). The hallmarks of aging. Cell 153, 1194-1217. doi: 10.1016/j.cell.2013.05.039

Madeo, F., Carmona-Gutierrez, D., Hofer, S. J., and Kroemer, G. (2019). Caloric restriction mimetics against age-associated disease: targets, mechanisms, and therapeutic potential. Cell Metab. 29, 592-610. doi: 10.1016/j.cmet.2019.01.018

Madeo, F., Eisenberg, T., Pietrocola, F., and Kroemer, G. (2018). Spermidine in health and disease. Science 359:eaan2788. doi: 10.1126/science.aan2788

Madeo, F., Zimmermann, A., Maiuri, M. C., and Kroemer, G. (2015). Essential role for autophagy in life span extension. J. Clin. Invest. 125, 85-93. doi: 10.1172/ JCI73946

Madreiter-Sokolowski, C. T., Sokolowski, A. A., Waldeck-Weiermair, M., Malli, R., and Graier, W. F. (2018). Targeting mitochondria to counteract age-related cellular dysfunction. Genes 9:165. doi: 10.3390/genes9030165

Mai, S., Klinkenberg, M., Auburger, G., Bereiter-Hahn, J., and Jendrach, M. (2010). Decreased expression of Drp1 and Fis1 mediates mitochondrial elongation in senescent cells and enhances resistance to oxidative stress through PINK1. J. Cell Sci. 123, 917-926. doi: 10.1242/jcs.059246

Mäkelä, J., Tselykh, T. V., Kukkonen, J. P., Eriksson, O., Korhonen, L. T., and Lindholm, D. (2016). Peroxisome proliferator-activated receptor- $\gamma$ (PPAR $\gamma$ ) agonist is neuroprotective and stimulates PGC- $1 \alpha$ expression and CREB 
phosphorylation in human dopaminergic neurons. Neuropharmacology 102, 266-275. doi: 10.1016/j.neuropharm.2015.11.020

Mariño, G., Pietrocola, F., Eisenberg, T., Kong, Y., Malik, S. A., Andryushkova, A., et al. (2014). Regulation of autophagy by cytosolic acetyl-coenzyme A. Mol. Cell 53, 710-725. doi: 10.1016/j.molcel.2014.01.016

Martens, S., and Fracchiolla, D. (2020). Activation and targeting of ATG8 protein lipidation. Cell Discov. 6:23. doi: 10.1038/s41421-020-0155-1

Martin-Montalvo, A., Mercken, E. M., Mitchell, S. J., Palacios, H. H., Mote, P. L., Scheibye-Knudsen, M., et al. (2013). Metformin improves healthspan and lifespan in mice. Nat. Commun. 4:2192. doi: 10.1038/ncomms 3192

Matsunaga, K., Saitoh, T., Tabata, K., Omori, H., Satoh, T., Kurotori, N., et al. (2009). Two Beclin 1-binding proteins, Atg14L and Rubicon, reciprocally regulate autophagy at different stages. Nat. Cell Biol. 11, 385-396. doi: 10.1038/ ncb1846

Medina, D. L., Di Paola, S., Peluso, I., Armani, A., De Stefani, D., Venditti, R., et al. (2015). Lysosomal calcium signalling regulates autophagy through calcineurin and TFEB. Nat. Cell Biol. 17, 288-299. doi: 10.1038/ncb3114

Melendez, A. (2003). Autophagy genes are essential for dauer development and life-span extension in C. elegans. Science 301, 1387-1391. doi: 10.1126/science. 1087782

Meng, Z., Shen, B., Gu, Y., Wu, Z., Yao, J., Bian, Y., et al. (2018). Diazoxide ameliorates severity of experimental osteoarthritis by activating autophagy via modulation of the osteoarthritis-related biomarkers. J. Cell. Biochem. 119, 8922-8936. doi: $10.1002 / j \mathrm{jcb} .27145$

Morselli, E., Maiuri, M. C., Markaki, M., Megalou, E., Pasparaki, A., Palikaras, K., et al. (2010a). Caloric restriction and resveratrol promote longevity through the Sirtuin-1-dependent induction of autophagy. Cell Death Dis. 1:e10. doi: $10.1038 /$ cddis. 2009.8

Morselli, E., Maiuri, M. C., Markaki, M., Megalou, E., Pasparaki, A., Palikaras, $\mathrm{K}$., et al. (2010b). The life span-prolonging effect of sirtuin-1 is mediated by autophagy. Autophagy 6, 186-188. doi: 10.4161/auto.6.1.10817

Murphy, C. T., McCarroll, S. A., Bargmann, C. I., Fraser, A., Kamath, R. S., Ahringer, J., et al. (2003). Genes that act downstream of DAF-16 to influence the lifespan of Caenorhabditis elegans. Nature 424, 277-283. doi: 10.1038/ nature 01789

Nakamura, S., Oba, M., Suzuki, M., Takahashi, A., Yamamuro, T., Fujiwara, M., et al. (2019). Suppression of autophagic activity by Rubicon is a signature of aging. Nat. Commun. 10:847. doi: 10.1038/s41467-019-08729-6

Neff, F., Flores-Dominguez, D., Ryan, D. P., Horsch, M., Schröder, S., Adler, T., et al. (2013). Rapamycin extends murine lifespan but has limited effects on aging. J. Clin. Invest. 123, 3272-3291. doi: 10.1172/JCI6 7674

Ong, S.-B., Subrayan, S., Lim, S. Y., Yellon, D. M., Davidson, S. M., and Hausenloy, D. J. (2010). Inhibiting mitochondrial fission protects the heart against ischemia/reperfusion injury. Circulation 121, 2012-2022. doi: 10.1161/ CIRCULATIONAHA.109.906610

Ouyang, L., Zhang, L., Zhang, S., Yao, D., Zhao, Y., Wang, G., et al. (2018). Small-molecule activator of UNC-51-Like Kinase 1 (ULK1) that induces cytoprotective autophagy for parkinson's disease treatment. J. Med. Chem. 61, 2776-2792. doi: 10.1021/acs.jmedchem.7b01575

Palikaras, K., Lionaki, E., and Tavernarakis, N. (2015). Coordination of mitophagy and mitochondrial biogenesis during ageing in C. elegans. Nature 521, 525-528. doi: $10.1038 /$ nature 14300

Plomp, P. J., Gordon, P. B., Meijer, A. J., Høyvik, H., and Seglen, P. O. (1989). Energy dependence of different steps in the autophagic-lysosomal pathway. J. Biol. Chem. 264, 6699-6704.

Pugh, T. D., Conklin, M. W., Evans, T. D., Polewski, M. A., Barbian, H. J., Pass, R., et al. (2013). A shift in energy metabolism anticipates the onset of sarcopenia in rhesus monkeys. Aging Cell 12, 672-681. doi: 10.1111/acel.12091

Pyo, J.-O., Yoo, S.-M., Ahn, H.-H., Nah, J., Hong, S.-H., Kam, T.-I., et al. (2013). Overexpression of Atg5 in mice activates autophagy and extends lifespan. Nat. Commun. 4:2300. doi: 10.1038/ncomms3300

Qi, X., Qvit, N., Su, Y.-C., and Mochly-Rosen, D. (2013). A novel Drp1 inhibitor diminishes aberrant mitochondrial fission and neurotoxicity. J. Cell Sci. 126, 789-802. doi: $10.1242 /$ jcs. 114439

Rana, A., Oliveira, M. P., Khamoui, A. V., Aparicio, R., Rera, M., Rossiter, H. B., et al. (2017). Promoting Drp1-mediated mitochondrial fission in midlife prolongs healthy lifespan of Drosophila melanogaster. Nat. Commun. 8:448. doi: 10.1038/s41467-017-00525-4

Rana, A., Rera, M., and Walker, D. W. (2013). Parkin overexpression during aging reduces proteotoxicity, alters mitochondrial dynamics, and extends lifespan. Proc. Natl. Acad. Sci. U.S.A. 110, 8638-8643. doi: 10.1073/pnas.1216197110

Rea, S. L., Ventura, N., and Johnson, T. E. (2007). Relationship between mitochondrial electron transport chain dysfunction, development, and life extension in Caenorhabditis elegans. PLoS Biol. 5:e259. doi: 10.1371/journal. pbio.0050259

Ristow, M. (2014). Unraveling the truth about antioxidants: mitohormesis explains ROS-induced health benefits. Nat. Med. 20, 709-711. doi: 10.1038/nm.3624

Robida-Stubbs, S., Glover-Cutter, K., Lamming, D. W., Mizunuma, M., Narasimhan, S. D., Neumann-Haefelin, E., et al. (2012). TOR signaling and rapamycin influence longevity by regulating SKN-1/Nrf and DAF-16/FoxO. Cell Metab. 15, 713-724. doi: 10.1016/j.cmet.2012.04.007

Rusmini, P., Cortese, K., Crippa, V., Cristofani, R., Cicardi, M. E., Ferrari, V., et al. (2019). Trehalose induces autophagy via lysosomal-mediated TFEB activation in models of motoneuron degeneration. Autophagy 15, 631-651. doi: 10.1080/ 15548627.2018.1535292

Ryu, D., Mouchiroud, L., Andreux, P. A., Katsyuba, E., Moullan, N., Nicolet-DitFélix, A. A., et al. (2016). Urolithin A induces mitophagy and prolongs lifespan in C. elegans and increases muscle function in rodents. Nat. Med. 22, 879-888. doi: $10.1038 / \mathrm{nm} .4132$

Sacitharan, P. K., Bou-Gharios, G., and Edwards, J. R. (2020). SIRT1 directly activates autophagy in human chondrocytes. Cell Death Discov. 6:41. doi: 10. 1038/s41420-020-0277-0

Sekine, S., and Youle, R. J. (2018). PINK1 import regulation; a fine system to convey mitochondrial stress to the cytosol. BMC Biol. 16:2. doi: 10.1186/s12915-0170470-7

Semba, R. D., Nicklett, E. J., and Ferrucci, L. (2010). Does accumulation of advanced glycation end products contribute to the aging phenotype? J. Gerontol. A. Biol. Sci. Med. Sci. 65A, 963-975. doi: 10.1093/gerona/glq074

Setua, S., Enguita, F. J., Chora, ÂF., Ranga-prasad, H., Lahree, A., Marques, S., et al. (2020). Disrupting Plasmodium UIS3-host LC3 interaction with a small molecule causes parasite elimination from host cells. Commun. Biol. 3:688. doi: 10.1038/s42003-020-01422-1

Shamalnasab, M., Gravel, S.-P., St-Pierre, J., Breton, L., Jäger, S., and Aguilaniu, H. (2018). A salicylic acid derivative extends the lifespan of Caenorhabditis elegans by activating autophagy and the mitochondrial unfolded protein response. Aging Cell 17:e12830. doi: 10.1111/acel.12830

Shibata, M., Lu, T., Furuya, T., Degterev, A., Mizushima, N., Yoshimori, T., et al. (2006). Regulation of intracellular accumulation of mutant huntingtin by beclin 1. J. Biol. Chem. 281, 14474-14485. doi: 10.1074/jbc.M600364200

Shirakabe, A., Zhai, P., Ikeda, Y., Saito, T., Maejima, Y., Hsu, C.-P., et al. (2016). Drp1-dependent mitochondrial autophagy plays a protective role against pressure overload-induced mitochondrial dysfunction and heart failure. Circulation 133, 1249-1263. doi: 10.1161/CIRCULATIONAHA.115.020502

Shoji-Kawata, S., Sumpter, R., Leveno, M., Campbell, G. R., Zou, Z., Kinch, L., et al. (2013). Identification of a candidate therapeutic autophagy-inducing peptide. Nature 494, 201-206. doi: 10.1038/nature11866

Simmen, T., and Herrera-Cruz, M. S. (2018). Plastic mitochondria-endoplasmic reticulum (ER) contacts use chaperones and tethers to mould their structure and signaling. Curr. Opin. Cell Biol. 53, 61-69. doi: 10.1016/j.ceb.2018.04.014

Simonsen, A., Cumming, R. C., Brech, A., Isakson, P., Schubert, D. R., and Finley, K. D. (2008). Promoting basal levels of autophagy in the nervous system enhances longevity and oxidant resistance in adult Drosophila. Autophagy 4, 176-184. doi: 10.4161/auto.5269

Song, M., Franco, A., Fleischer, J. A., Zhang, L., and Dorn, G. W. (2017). Abrogating mitochondrial dynamics in mouse hearts accelerates mitochondrial senescence. Cell Metab. 26, 872.e5-883.e5. doi: 10.1016/j.cmet.2017.09.023

Sun, Y., Yao, X., Zhang, Q.-J., Zhu, M., Liu, Z.-P., Ci, B., et al. (2018). Beclin1-dependent autophagy protects the heart during sepsis. Circulation 138, 2247-2262. doi: 10.1161/CIRCULATIONAHA.117.032821

Taneike, M., Yamaguchi, O., Nakai, A., Hikoso, S., Takeda, T., Mizote, I., et al. (2010). Inhibition of autophagy in the heart induces age-related cardiomyopathy. Autophagy 6, 600-606. doi: 10.4161/auto.6.5.11947

Tavallaie, M., Voshtani, R., Deng, X., Qiao, Y., Jiang, F., Collman, J. P., et al. (2020). Moderation of mitochondrial respiration mitigates metabolic syndrome 
of aging. Proc. Natl. Acad. Sci. U.S.A. 117, 9840-9850. doi: 10.1073/pnas. 1917948117

Thomas, H. E., Zhang, Y., Stefely, J. A., Veiga, S. R., Thomas, G., Kozma, S. C., et al. (2018). Mitochondrial complex I activity is required for maximal autophagy. Cell Rep. 24, 2404.e8-2417.e8. doi: 10.1016/j.celrep.2018.07.101

Tóth, M. L., Sigmond, T., Borsos, É, Barna, J., Erdélyi, P., Takács-Vellai, K., et al. (2008). Longevity pathways converge on autophagy genes to regulate life span in Caenorhabditis elegans. Autophagy 4, 330-338. doi: 10.4161/auto.5618

Touvier, T., De Palma, C., Rigamonti, E., Scagliola, A., Incerti, E., Mazelin, L., et al. (2015). Muscle-specific Drp1 overexpression impairs skeletal muscle growth via translational attenuation. Cell Death Dis. 6:e1663. doi: 10.1038/cddis.2014.595

Tyrrell, D. J., Blin, M. G., Song, J., Wood, S. C., Zhang, M., Beard, D. A., et al. (2020). Age-associated mitochondrial dysfunction accelerates atherogenesis. Circ. Res. 126, 298-314. doi: 10.1161/CIRCRESAHA.119.315644

Wang, C., Niederstrasser, H., Douglas, P. M., Lin, R., Jaramillo, J., Li, Y., et al. (2017). Small-molecule TFEB pathway agonists that ameliorate metabolic syndrome in mice and extend C. elegans lifespan. Nat. Commun. 8:2270. doi: 10.1038/s41467-017-02332-3

Westermann, B. (2015). The mitochondria-plasma membrane contact site. Curr. Opin. Cell Biol. 35, 1-6. doi: 10.1016/j.ceb.2015.03.001

Whitehead, N., Gill, J. F., Brink, M., and Handschin, C. (2018). Moderate modulation of cardiac PGC- $1 \alpha$ expression partially affects age-associated transcriptional remodeling of the heart. Front. Physiol. 9:242. doi: 10.3389/ fphys.2018.00242

Wiersma, M., Henning, R. H., and Brundel, B. J. J. M. (2016). Derailed proteostasis as a determinant of cardiac aging. Can. J. Cardiol. 32, .e11-.e1166. doi: 10.1016/ j.cjca.2016.03.005

Wong, Y. C., Ysselstein, D., and Krainc, D. (2018). Mitochondria-lysosome contacts regulate mitochondrial fission via RAB7 GTP hydrolysis. Nature 554, 382-386. doi: 10.1038/nature25486

Yang, S., Loro, E., Wada, S., Kim, B., Tseng, W.-J., Li, K., et al. (2020). Functional effects of muscle PGC-1alpha in aged animals. Skelet. Muscle 10:14. doi: 10. 1186/s13395-020-00231-8

Yang, X., Zhang, M., Dai, Y., Sun, Y., Aman, Y., Xu, Y., et al. (2020). Spermidine inhibits neurodegeneration and delays aging via the PINK1-PDR1-dependent mitophagy pathway in C. elegans. Aging 12, 16852-16866. doi: 10.18632/aging. 103578

Yi, C., Ma, M., Ran, L., Zheng, J., Tong, J., Zhu, J., et al. (2012). Function and molecular mechanism of acetylation in autophagy regulation. Science 336, 474-477. doi: 10.1126/science. 1216990

Yin, Z., Pascual, C., and Klionsky, D. J. (2016). Autophagy: machinery and regulation. Microb. Cell Graz Austria 3, 588-596. doi: 10.15698/mic2016.12.546

Zhang, H., Alsaleh, G., Feltham, J., Sun, Y., Napolitano, G., Riffelmacher, T., et al. (2019). Polyamines control eIF5A Hypusination, TFEB translation, and autophagy to reverse B cell senescence. Mol. Cell 76, 110.e9-125.e9. doi: 10. 1016/j.molcel.2019.08.005

Zheng, B., Liao, Z., Locascio, J. J., Lesniak, K. A., Roderick, S. S., Watt, M. L., et al. (2010). PGC-1 $\alpha$, a potential therapeutic target for early intervention in Parkinson's disease. Sci. Transl. Med. 2:52ra73. doi: 10.1126/scitranslmed. 3001059

Zhou, B., Kreuzer, J., Kumsta, C., Wu, L., Kamer, K. J., Cedillo, L., et al. (2019). Mitochondrial permeability uncouples elevated autophagy and lifespan extension. Cell 177, 299.e16-314.e16. doi: 10.1016/j.cell.2019.02. 013

Zhu, X., Shen, W., Yao, K., Wang, H., Liu, B., Li, T., et al. (2019). Fine-tuning of PGC1 $\alpha$ expression regulates cardiac function and longevity. Circ. Res. 125, 707-719. doi: 10.1161/CIRCRESAHA.119.315529

Conflict of Interest: The authors declare that the research was conducted in the absence of any commercial or financial relationships that could be construed as a potential conflict of interest.

Copyright (c) 2021 Zimmermann, Madreiter-Sokolowski, Stryeck and Abdellatif. This is an open-access article distributed under the terms of the Creative Commons Attribution License (CC BY). The use, distribution or reproduction in other forums is permitted, provided the original author(s) and the copyright owner(s) are credited and that the original publication in this journal is cited, in accordance with accepted academic practice. No use, distribution or reproduction is permitted which does not comply with these terms. 